spnedig kan worden tegemoetgezien, wordt de wensch geuit bij de voorrede van den Schrijver der Atjehsche Spraakkunst eene verklaring van het Bestuur te voegen, waaruit zijn aandeel en verantwoordelijkheid bij de uitgave van het werk duidelijk kunnen blijken. Dienovereenkomstig wordt besloten en de Secretaris gemachtigd daaromtrent met den heer Snouck Hurgronje in overleg te treden.

Niets meer hierna aan de orde zijnde, wordt de vergadering door de Voorzitter gesloten.

\title{
300sTE BESTUURSVERGADERING
}

GEHOUDEN 16 FEBRUARI 1889.

Tegenwoordig de hh. Kern (Voorzitter), Kielstra (Ondervoorzitter), J. H. de Groot (Penningmeester), Bool, Martin Snouck Hurgronje, Wilken, Humme, Niemann, de Roo en Wijnmalen (Secretaris). Afwezig, met kennisgeving, de heer Riedel.

De notulen van het verhandelde in de vorige vergadering worden gelezen en goedgekeurd.

De Secretaris doet opgave van de sedert de vorige bijeenkomst ontvangen en ter tafel aanwezige boekwerken. Aangenomen voor kennisgeving en plaatsing der werken in de Bibliotheek, onder dankbetuiging aan de inzenders.

De Voorzitter deelt mede, dat zijn ontvangen :

10. eene missive van den Secretaris-Generaal van de Académie Royale des sciences de Lisbonne, dd. Januari jl., houdende dankbetuiging voor de ontvangst der toegezonden 4,e aflevering van deel III, 5e volgreeks der Bijdragen. Voor kennisgeving aangenomen.

20. twee missives van de Commissarissen van het Internationaal geographisch Congres, dat van 5 tot 11 Augustus 1889 te Parijs 
zal gehouden worden, bevattende mededeelingen omtrent dat Congres. Voor kennisgeving aangenomen.

30. eene missive van Mevr. de Wed. A. C. Tiele-ter Meulen, houdende bericht van het overlijden van haren Echtgenoot Dr. P. A. Tiele, in leven Bibliothecaris der Rijks-Universiteit te Utrecht en correspondeerend lid van het Instituut

Wordt besloten dit schrijven met een brief van rouwbeklag te beantwoorden, terwijl de Voorzitter hulde brengt aan de veelzijdige verdiensten van het overleden medelid en zijne hooggewaardeerde belangstelling in de werkzaamheden van het Instituut.

4.c. missives van de heeren A. L. H. Badings, C. H. de Goeje, J. H. Paunekoek en J. N. A. Baron Taets van Amerongen, allen houdende kennisgeving, dat zij met het einde van het loopende jaar van de lijst der leden van het Instituut wenschen afgevoerd te worden.

Hiervan zal aanteekening worden gehouden.

5o. eene missive van mr. A. C. P. Lammers van Toorenburg, te 's Gravenhage, houdende bericht van de aanvaarding van het lidmaatschap van het Instituut.

Aangenomen voor kennisgeving.

$6^{\circ}$. twee missives van den Minister van Buitenlandsche Zaken dd. 1 en 6 Februari jl. 10 afd. no. 1054 en no. 1247, waarbij, ten vervolge, worden aangeboden:

a. een uittreksel uit een aan Zr. Ms. Gezant te Londen gerichten brief van den heer J. van den Pauwert Canter Visscher, dd. Calcutta 2 December 1888, ten geleide strekkende van de mede bijgevoegde opgaven nopens grafmonumenten van Nederlanders te Cassimbazar in Bengalen; en

b. een door den Consul-Generaal der Nederlanden te New-York aan het Instituut aangeboden exemplaar eener brochure, getiteld: "New Amsterdam, New-York, New Orange."

Beide stukken worden in handen gesteld van het Bestuurslid Bool.

De Secretaris deelt der Vergadering mede, dat het tweede deel van Dr. Snouck's "Mekka" gereed is, terwijl de geheele oplaag daarvan door de firma Brill aan onzen Uitgever M. Nijhoff is 
afgeleverd; de voor het departement van Koloniën bestemde honderd exemplaren zijn bereids verzonden, waarvan het door genoemd Departement afgegeven bewijs van ontvangst wordt overgelegd. Inmiddels was ook aan dat Departement eene declaratie voor de kosten daarvan tot een bedrag van $f 750$ ingediend, waarvoor bereids een mandaat tot kwijting dier som werd ontvangen, dat, na onderteekening door Voorzitter en Secretaris, aan den Penningmeester is ter hand gesteld.

De Voorzitter grijpt deze gelegenheid aan om den heer Snouck Hurgronje geluk te wenschen met de voltooiing van zijnen belangrijken en veelomvattenden arbeid, die een der sieraden zal uitmaken onder de uitgaven van het Instituut, terwijl de bijval, die daaraan reeds zoowel hier te lande als in den vreemde mocht ten deel vallen, voor hem eene ware voldoening moet zijn en goede hoop geeft voor de toekomst, waar hij gereed staat, overeenkomst de opdracht der Regeering, zijne onderzoekingen in Jndië voort te zetten.

De heer Snouck Hurgronje dankt den Voorzitter voor zijne welwillende woorden en niet het minst voor den steun, dien hij bij zijn arbeid vanwege het Instituut mocht ondervinden.

De Secretaris herinnert dat in de eerstvolgende aflevering der Bijdragen, overeenkomstig het advies der heeren Wilken en Kern, een opstel van Dr. Grabowsky zal geplaatst worden in de Duitsche taal, waaraan echter eenige aanteekeningen vanwege de Redactie moeten worden gevoegd, die naar hare meening eveneens in het Duitsch behooren gesteld te worden, doch waaromtrent verschil van opvatting schijnt te bestaan.

$\mathrm{Na}$ eenige gedachtenwisseling en gehoord de inlichtingen van den Voorzitter en den heer Wilken omtrent het door hen, in afwijking van het door den Secretaris-Redacteur, ingenomen standpunt, wordt besloten in het nu reeds gedrukte stuk des heeren Grabowsky geene wijziging meer te maken, doch voor het vervolg als beginsel aan te nemen, dat, mocht de Redactie termen vinden bij een in een vreemde taal geschreven stuk noten te voegen, deze alsdan in de moedertaal te plaatsen.

Naar aanleiding van het in de vorige vergadering genomen besluit deelt de Secretaris mede, dat bij het met den heer Martin gehouden overleg geen bezwaar is gerezen tegen de plaatsing; in de eerstvolgende aflevering der Bijdragen, van het door den heer Dr. ten 
Kate aangeboden opstel, terwijl bereids met den heer Trap in onderhandeling is getreden omtrent de vervaardiging van een achttal daarbij behoorende platen, waarvan de kosten kunnen worden gekweten uit de voor den druk der Bijdragen toegestane som.

Een en ander wordt voor kennisgeving aangenomen.

De Commissie, bestaande uit de hh. Humme en Kielstra, aan wie in de vorige vergadering was opgedragen de rekening van den Penningmeester over 1888 te onderzoeken, brengt, bij monde van eerstgenoemde, daaromtrent verslag uit. $\mathrm{Zij}$ heeft al de bescheiden nauwkeurig nagegaan en alles in goede orde bevonden, waarom zij niet aarzelt voor te stellen de aangeboden rekening vanwege het Bestuur goed te keuren onder dankbetuiging aan den Penningmeester voor zijn beheer. Zonder beraadslaging wordt dienovereenkomstig besloten.

Door den Secretaris wordt ter tafel gebracht het ontwerp van het door hem namens het Bestuur uit te brengen Verslag omtrent den staat en de werkzaamhedeu van het Instituut over het verloopen jaar. Met eenige wijzigingen wordt het door de vergadering goedgekeurd, onder dankzegging voor den geleverden arbeid.

De vergadering gaat hierna over tot de bespreking en het opmaken van de aan de Algemeene vergadering aan te bieden drietallen ter voorziening in de vacatures door de aftreding van de bestuursleden Humme, de Roo, Riedel en Snouck Hurgronje. Uit de gehouden stemming blijkt, dat zullen worden voorgedragen:

voor de vacature-H. C. Humme, de hh. D. F. van der Pant, te Leiden, J. Habbema, te Nijmegen en W. van Gelder, te 's Gravenhage;

voor de vacature-Dr. L. W. G. de Roo, de hh.: Mr. W. Baron - van Goltstein, Mr. S. H. Nederburgh, en Mr. H. D. Levyssohn Norman, allen te 's Gravenhage;

voor de vacature-Dr. J. F. G. Riedel, de hh.: Prof. Dr. G. Schlegel, te Leiden, Prof. Dr. C. M. Kan, te Amsterdam en Mr. O. J. H. Graaf van Limburg Stirum, te 's Gravenhage; en

voor de vacature-Dr. C. Snouck Hurgronje, de hh.: Prof. Mr. P. A. van der Lith, Prof. Dr. M. J. de Goeje, te Leiden, Dr. B. F. Matthes, te 's Gravenhage.

De Voorzitter zegt den aftredenden Bestuursleden dank vooir de vele blijken van belangstelling, welke het Instituut hunnerzijds mocht ondervinden en beveelt de bevordering zijner belangen in hunne voortdurende welwillendheid aan. 
Tot buitenlandsche leden van het Instituut worden vervolgens voorgedragen en benoemd de hh.:

Prof. Dr. Edward B. Tylor, te Oxford.

Dr. Ignaz Goldziher, Privaat-Docent aan de Universiteit te Budapest.

Dr. Freiherr von Richthofen, Gewoon Hoogleeraar te Berlijn.

Tot gewone leden in Nederland de hh. :

Jhr. Mr. K. A. Godin de Beaufort. Minister van Financiën, te 's Gravenhage.

H. Dyserinck, Minister van Marine, te 's Gravenhage.

Mr. H. J. Smidt, Oud-Gouverneur van Suriname te 's Gravenhage,

W. J. Geertsema, te Amsterdam,

Mr. W. J. Roogaards van den Ham, te Utrecht,

S. T. Land, te 's Gravenhage,

Jhr. Mr. J. W. G. Boreel van Hogelanden, te Velzen, - allen Leden van de Tweede Kamer der Staten-Generaal.

Mr. B. M. Vlielander Hein, te 's Gravenhage,

H. G. L. Regout, te Maastricht, - leden van de Eerste Kamer der Staten-Generaal.

Mr. C. J. A. Heydenrijck, Tid van den Raad van State, te 's Gravenhage.

Mr. A. R. Arntzenius, Griffier van de Tweede Kamer der StatenGeneraal, te 's Gravenhage.

Jhr. P. Hartsen, Directeur der Nederlandsche Handelmaatschappij, te Amsterdam.

Mr. H. L. M. Luden, 's Konings Gedelegeerde bij de Ned. Handelmaatschappij, te Amsterdam.

M. C. Calkoen, Directeur der Koloniale Bank, te Amsterdam.

W. Ruys, Lid der firma W. Ruys en Zoon, Directeur der Stoomvaartmaatschappij, Rotterdamsche Lloyd, te Rotterdam.

Dr. D. de Haan, President van de Maatschappij tot bevordering van Nijverheid, te Haarlem.

P. J. van Houten, te 's Gravenhage.

J. T. D. Bruinsma, Majoor der Infanterie bij het Indisch leger, te 's Gravenhage.

H. Catenius, Majoor bij het Ind. leger, met verlof, te Breda

W. R. de Greve, Oud-Indisch Ambtenaar, te 's Gravenhage.

R. E. de Haan, Directeur der Hoogere Burgerschool te Winterswijk.

Ch. Boissevain, Hoofdredacteur van het Algemeen Handelsblad, te Amsterdam. 
Dr. H. Bavinck, Hoogleeraar aan de Theologische School, te Kampen. Mr. C. A. Vaillant, Advocaat en Procureur te 's Gravenhage.

Mr. M. Massinck, Advocaat en Procureur te Amsterdam.

J. J. L. Heldring, Lid van de Kamer van Koophandel, te 's Gravenhage.

J. D. Oortman Gerlings, Bankier te Utrecht.

H. D. Pierson, Lid der firma Heldring \& Pierson, te 's Gravenhage.

D. A. van Heemskerk Veeckens, Oud-Zeeofficier, te Amsterdam.

H. T. van Steeden, te 's Gravenhage.

Dr. Hommo Tonkes, te Amsterdam.

Dr. H. Hartogh Heys van Zouteveen, te Assen.

E. F. T. Bik, Luitenant ter zee, te 's Gravenhage.

Mr. H. Zillesen, Secretaris der Koloniale Commissie voor de $\mathrm{Pa}$.* rịjsche 'Tentoonstelling, te 's Gravenhage.

A. H. Kuypers, Oud O. I. ambtenaar, te Haarlem.

Van deze benoemingen zal aan de Algemeene Vergadering mededeeling worden gedaan.

Met het oog op de weldra te verwachten uitgave van de Atjehsche Spraakkunst en het Atjehsch Woordenboek vraagt de Secretaris, in verband ook met een door hem ontvangen schrijven des heeren Nijhofl, tegen welken prijs beide werken moeten worden verkrijgbaar gesteld. $\mathrm{Na}$ eenige gedachtenwisseling wordt besloten, behoudens nader overleg met den heer Nijhoff, den prijs der Atjehsche Sprakkunst te stellen op ongeveer $f 2.50$, en dien van het Atjehsch Woordenboek op ongeveer $f 5.00$, terwijl, ingevolge besluit der vorige Algemeene Vergadering, de leden die werken tegen de helft van den handelsprijs kunnen verkrijgen.

Door den heer de Roo wordt verslag uitgebracht omirent een in zijne handen gesteld journaal van van Overstraten betreffende zijne reis naar de Kaap de Goede Hoop en Batavia. Het komt hem voor, dat het nog onuitgegeven handschrift bekende feiten meêdeelt, weswege het niet voor eene uitgave in aanmerking kan komen en aan den inzender, Mr. W. B. Bergsma, behoort te worden teruggezonden, tenzij dit mede-lid het voor onze verzameling van handschriften zou willen afstaan, waartoe de heer de Roo zich bereid verklaart eene poging te doen. Zonder beraadslaging wordt overeenkomstig dit praeadvies besloten.

Niets meer aan de orde zịjnde, sluit de Voorzitter de vergadering. 


\title{
ALGEMEENE VERGADERINGG,
}

GEHOUDEN 23 FEBRUARI 1889.

\begin{abstract}
Tegenwoordig de hh. Kern (Voorzitter), Kielstra (Ondervoorzitter), J. H. de Groot (Penningmeester), Wịnmalen (Secretaris), Matthes, Pleyte, ten Kate, Snouck Hurgronje, Schlegel, Wilken, Humme, Klerk de Reus, Bik, Niemann, Netscher, Kiehl, Harmsen en het correspondeerend lid Schmeltz.
\end{abstract}

De Voorzitter, Prof. Dr. H. Kern, opent de Vergadering en heet de leden welkom, waarbij de wensch wordt uitgesproken, dat de bijeenkomst vruchtbaar moge blijken te zijn ter bevordering van den bloei van het Instituut.

Van de leden H. J. Bool, Prof. Dr. A. Pierson en G. E. V. L. van Zuylen is bericht ontvangen, dat zij tot hun leed de Algemeene Vergadering niet kunnen bijwonen.

De notulen van het verhandelde in de vorige Algemeene Vergadering, welke voorloopig door het Bestuur goedgekeurd en bereids in de Bijdragen (5e R. III blz. LIII vlg.) afgedrukt zijn, worden voorgelezen, en, daar niemand daartegen eenige bedenking heeft, definitief vastgesteld.

Namens het Bestuur wordt door den Secretaris verslag uitgebracht over den staat en de werkzaamheden van het Instituut gedurende het afgeloopen jaar 1888 .

Onder toejuiching der Vergadering, zegt de Voorzitter hem dank voor den geleverden arbeid, terwijl, overeenkomstig zijn voorstel, met acclamatie besloten wordt het Verslag te doen drukken en opnemen in de eerstvolgende aflevering der Bijdragen. 